\title{
Selective Biochlorination of Hydroxyquinolines by a Flavin-Dependent Halogenase
}

\author{
Fuchao Xu ${ }^{\mathrm{a}}$, Amanda Merkley ${ }^{\mathrm{a}}$, Dayu $\mathrm{Yu}^{\mathrm{b}}$ and Jixun Zhan ${ }^{\mathrm{a}, *}$ \\ ${ }^{a}$ Department of Biological Engineering, Utah State University, 4105 Old Main Hill, Logan, UT 84322, USA \\ ${ }^{b}$ Viablife Biotech Co., Ltd., 1 Jing 'yi Road, Hangzhou, Zhejiang 311113, China
}

\section{ARTICLE INFO}

\section{Article history:}

Received

Received in revised form

Accepted

Available online

\section{Keywords:}

Chlorination

Hydroxyquinolines

Halogenase

Substrate specificity

Chlorohydroxyquinolines

\section{ABSTRACT}

Rdc2 is a flavin-dependent halogenase from Pochonia chlamydosporia. Through the introduction of a His6-tag to both the $\mathrm{N}$ - and C-termini, the isolation yield of Rdc 2 from Escherichia coli using Ni-NTA affinity chromatography was increased by three-fold. In vitro reaction of $\mathrm{Rdc} 2$ and a flavin reductase (Fre) with seven different hydroxyquinolines revealed that 3-hydroxyquinoline (3), 5-hydroxyquinoline (5), 6-hydroxyquinoline (6) and 7hydroxyquinoline (7) can be specifically halogenated. These products were prepared by incubating the corresponding substrates with IPTG-induced E. coli BL21(DE3)/Rdc2. They were respectively characterized as 3-hydroxy-4-chloroquinoline (3a), 5-hydroxy-6chloroquinoline (5a), 5-chloro-6-hydroxyquinoline (6a), and 7-hydroxy-8-chloroquinoline (7a) by NMR and MS analyses. This work represents the first enzymatic preparation of chlorohydroxyquinolines and provides a "green" method to synthesize this group of medicinally important compounds.

2016 Elsevier Ltd. All rights reserved.

\section{Introduction}

Quinolines are common building blocks of numerous bioactive molecules, such as camptothecin (anticancer), ${ }^{1}$ chloroquine (antimalarial), ${ }^{2}$ quinine (antimalarial), ${ }^{3}$ quinidine (antiarrhythmic), ${ }^{4}$ and montelukast (anti-asthma) shown in Figure 1. ${ }^{5}$ Hydroxyquinolines are used as versatile chelating agents and precursors to many pharmaceuticals and pesticides. ${ }^{6}$ For example, the derivatives of 8-hydroxyquinoline can be used as multi-target compounds for the treatment of Alzheimer's disease. ${ }^{7}$ Hydroxyquinolines can be chemically synthesized from quinoline

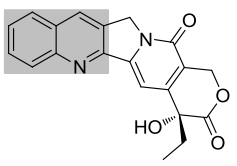

Camptothecin

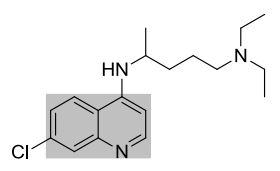

Chloroquine

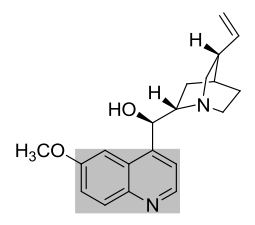

Quinine

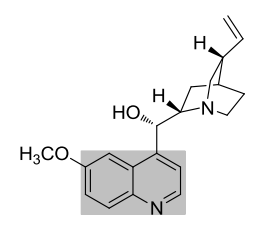

Quinidine
Figure 1. Quinoline-containing bioactive molecules. The quinoline moiety is shaded.

\section{(1, Figure 2).}

Halogenated compounds represent about 20\% of pharmaceuticals on the market and a quarter of those in the development pipeline. Chlorohydroxyquinolines are known to possess important medicinal properties. ${ }^{8}$ For example, it has been reported that 5-chloro-8-hydroxyquinoline has significant antimycoplasma activity. ${ }^{9}$ However, preparation of halogenated molecules relies on chemical methods. Chemical halogenation typically requires harsh reaction conditions including high temperatures and toxic reagents (such as chlorine gas, hydrochloric acid, and hydrogen peroxide). This is often accompanied by poor selectivity, which results in unspecific halogenation and undesired byproducts, creating difficulties in the purification process. ${ }^{10}$ For example, a previous research showed that chlorination of quinoline at $160-190{ }^{\circ} \mathrm{C}$ yielded a mixture of five chlorinated products, including 3,4dichloroquinoline, 3,4,6-trichloroquinoline, 3,4,8trichloroquinoline, 3,4,6,8-tetrachloroquinoline, and 3,4,6,7,8pentachloroquinoline. ${ }^{11}$

Biological halogenation is considered as a better approach for its high selectivity. Flavin-dependent halogenases are a major player in the introduction of halogen in the biosynthesis of halogenated natural products such as radicicol. ${ }^{12}$ Most reported flavin-dependent halogenases are prokaryotic tryptophan halogenases. The use of these enzymes in the preparation of halogenated molecules was limited due to their strict substrate specificity. A recent work reported that a tryptophan 6-

* Corresponding author. Tel.: +1-435-797-8774; fax: +1-435-797-2769; e-mail: jixun.zhan@usu.edu 
halogenase (Th-Fal) from a thermophilic halotolerant Streptomyces violaceusniger can halogenate several tryptophan derivatives and aromatic substrates, including methyltryptophan, 5-hydroxytryptophan, kynurenine, anthranilic acid, and anthranilamide. ${ }^{13}$ However, there is still a lack of a highly flexible halogenase that can be used for a broad range of substrates. Rdc2 is the first flavin-dependent halogenase identified from fungi. This enzyme is involved in the biosynthesis of radicicol, specifically chlorinating monocillins (a group of resorcylic acids) at C-6. Rdc2 was found to have flexible substrate specificity and can work on similar macrolactones and other structurally different compounds such as oxytetracycline and curcumin. ${ }^{14}$ A homology model of Rdc2 was built, which indicates that the space at the active site of this enzyme is large enough to accommodate different substrates. Two hydroxyisoquinolines were converted by Rdc 2 to two new halogenated derivatives. ${ }^{15}$ However, specific enzymatic preparation of chlorohydroxyquinolines has not been previously reported. In this work, we systematically tested the halogenation capability using seven monohydroxylated quinolines (2-8, Figure 2), including 2-hydroxyquinoline (2), 3-hydroxyquinoline (3), 4hydroxyquinoline (4), 5-hydroxyquinoline (5), 6hydroxyquinoline (6), 7-hydroxyquinoline (7), and 8hydroxyquinoline $(\mathbf{8})$.

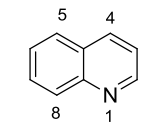

Quinoline (1)<smiles>Oc1ccnc2ccccc12</smiles>

4-Hydroxyquinoline (4)<smiles>Oc1ccc2cccnc2c1</smiles>

7-Hydroxyquinoline (7)<smiles>Oc1ccc2ccccc2n1</smiles><smiles>Oc1cnc2ccccc2c1</smiles>

2-Hydroxyquinoline (2)

3-Hydroxyquinoline (3)
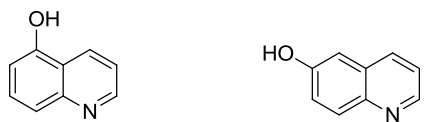

6-Hydroxyquinoline (6)
Figure 2. Structures of quinoline (1) and hydroxyquinolines (2-8).

\section{Results and discussion}

The reaction of Rdc2 requires a partner enzyme, flavin reductase (Fre), which reduces FAD to yield $\mathrm{FADH}_{2}$. We previously constructed pZJ54 (pET28a-rdc2) and pZJ62 (pET28a-fre) to purify $\mathrm{N}$-His 6 -tagged enzymes for in vitro reactions. ${ }^{14}$ In order to get a higher Rdc2 yield, we designed a construct with a His6-tag at both $\mathrm{N}$ - and C-terminal ends. To this end, the intron-free $r d c 2$ gene was amplified from the previously constructed pZJ54 by PCR with Phusion High-Fidelity DNA Polymerase (New England Biolabs) using a pair of specific primers, 5'-aaCATATGTCGGTACCCAAGTCTTG-3' (the NdeI site is underlined) and $5^{\prime}$ aaAAGCTTAACTTTGTTGAGGCCAA-3' (the HindIII site is underlined). The amplified gene was ligated into the cloning

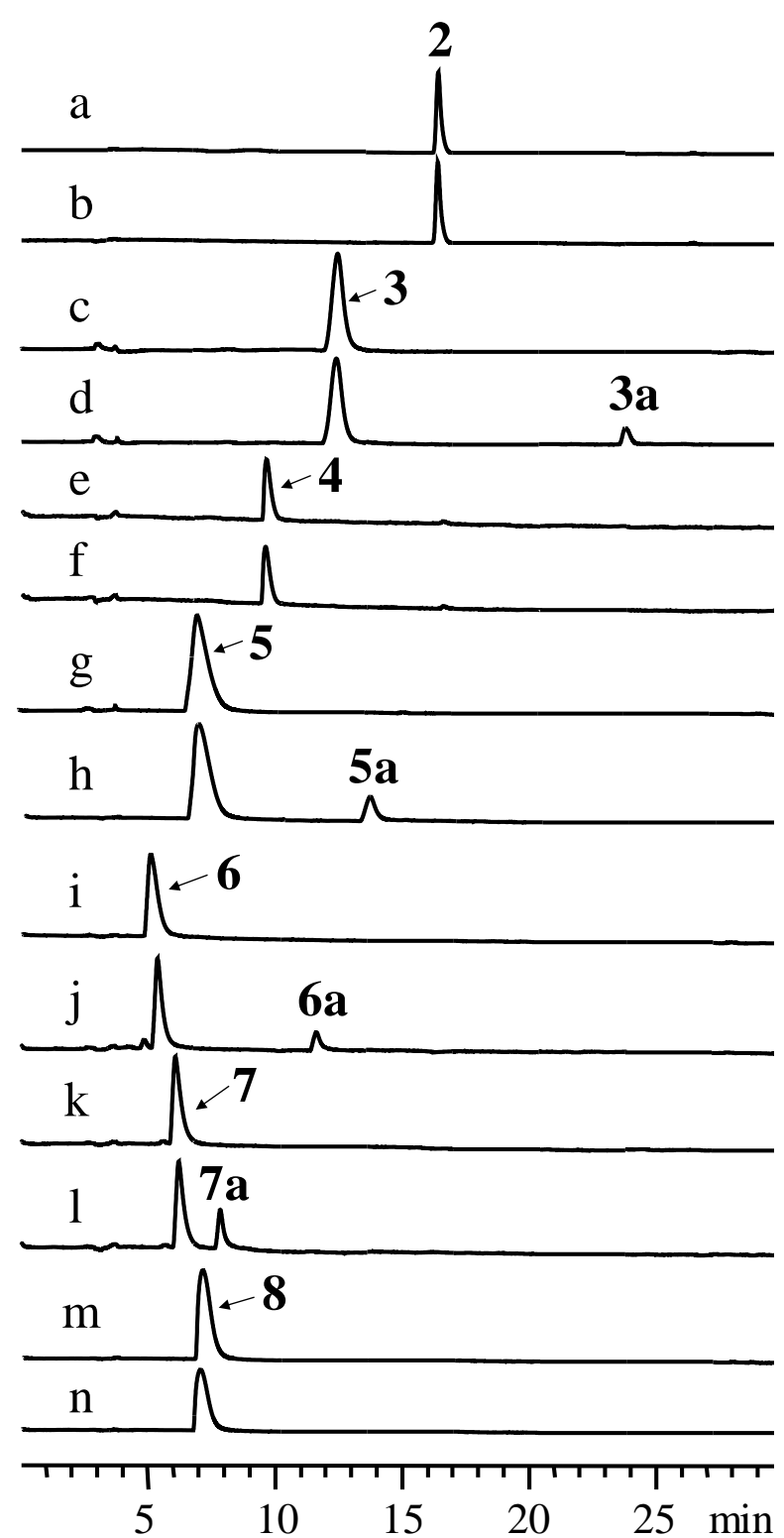

Figure 3. HPLC analysis (at $250 \mathrm{~nm}$ ) of the in vitro reactions of Rdc2 with hydroxyquinolines (at $30^{\circ} \mathrm{C}$ for $2 \mathrm{~h}$ ) in the presence of Fre, NADH, FAD, $\mathrm{O}_{2}$ and $\mathrm{NaCl}$. (a) Inactivated $\mathrm{Rdc} 2+\mathbf{2}$; (b) $\mathrm{Rdc} 2+\mathbf{2}$; (c) Inactivated Rdc2 + 3; (d) Rdc2 + 3; (e) Inactivated Rdc2 + 4; (f) Rdc2 + 4; (g) Inactivated Rdc2 + 5; (h) Rdc2 + 5; (i) Inactivated Rdc2 + 6; (j) $\mathrm{Rdc} 2+\mathbf{6}$; (k) Inactivated Rdc2 + 7; (1) Rdc2 + 7; (m) Inactivated Rdc2 + $\mathbf{8} ;$ (n) $\operatorname{Rdc} 2+\mathbf{8}$.

vector pJET1.2 to yield pFC55. The Rdc2 gene was then excised from pFC55 with NdeI and HindIII and ligated into pET28a between the same sites to generate pFC56.

The plasmid pFC56 was introduced into E. coli BL21(DE3) for protein expression. The resulting strain was grown at $37{ }^{\circ} \mathrm{C}$ in Luria-Bertani (LB) medium supplemented with $50 \mu \mathrm{g} \mathrm{mL}$ kanamycin. Protein expression was induced at $\mathrm{OD}_{600}$ 0.4-0.6 with $200 \mu \mathrm{M}$ isopropyl-1-thio- $\beta$-D-galactopyranoside (IPTG). The

Table 1. ${ }^{1} \mathrm{H}(500 \mathrm{MHz}) \mathrm{NMR}$ data for 3a, 5a, 6a and $7 \mathbf{a}\left(\mathrm{CD}_{3} \mathrm{OD}, \delta\right.$ in ppm, $J$ in $\left.\mathrm{Hz}\right)$.

\begin{tabular}{llll}
\hline Position & \multicolumn{1}{c}{ 3a } & \multicolumn{1}{c}{ 5a } & \multicolumn{1}{c}{ 6a } \\
\hline 2 & $8.62(1 \mathrm{H}, \mathrm{s})$ & $8.83(1 \mathrm{H}, \mathrm{d}, J=3.0)$ & $8.80(1 \mathrm{H}, \mathrm{d}, J=4.4)$ \\
3 & - & $7.56(1 \mathrm{H}, \mathrm{dd}, J=8.5,4.0)$ & $7.59(1 \mathrm{H}, \mathrm{dd}, J=8.4,4.1)$ \\
4 & - & $8.72(1 \mathrm{H}, \mathrm{d}, J=8.5)$ & $8.49(1 \mathrm{H}, \mathrm{d}, J=8.4)$ \\
5 & $8.17(1 \mathrm{H}, \mathrm{d}, J=7.9)$ & - & -
\end{tabular}


double His ${ }_{6}$-tagged Rdc2 was purified by Ni-NTA column at a yield of $18.5 \mathrm{mg} \mathrm{L}^{-1}$, which represents a three-fold increase compared to the N-terminal His 6 -tagged Rdc2. ${ }^{14}$ The plasmid pZJ62 was introduced into E. coli BL21-CodonPlus (DE3)-RIL for the purification of Fre, as previously reported. ${ }^{14}$ Both enzymes were stored in $50 \%$ glycerol at $-20^{\circ} \mathrm{C}$.

We then conducted in vitro enzymatic assays with Rdc2, Fre, $\mathrm{NADH}, \mathrm{FAD}, \mathrm{NaCl}, \mathrm{O}_{2}$ and seven different hydroxyquinolines 28 as substrates. The reactions were incubated at $30^{\circ} \mathrm{C}$ for $2 \mathrm{~h}$ and the negative controls were maintained under the same conditions with inactivated Rdc2. As shown in Figure 3, HPLC analysis revealed that $\mathbf{3}, \mathbf{5}, \mathbf{6}$ and $\mathbf{7}$ can be converted to less polar products 3a, 5a, $\mathbf{6 a}$ and $7 \mathbf{a}$ by Rdc2, respectively. By contrast, no products were synthesized from 2,4 and 8 . A comparison of the UV spectra of $3 \mathbf{a}, 5 \mathbf{a}, \mathbf{6 a}$ and $7 \mathbf{a}$ with the corresponding substrates showed a bathochromic shift (Figure S1), indicating that these products are chlorinated derivatives of $\mathbf{3}, \mathbf{5}, \mathbf{6}$ and 7. ESI-MS of all these products showed the $[\mathrm{M}+\mathrm{H}]^{+}$quasimolecular peaks at $\mathrm{m} / z, 182$ and 180, with a ratio of 3:1 (Figure S2), representing a characteristic isotope pattern of monochlorinated compounds. All the hydroxyquinolines are isomers with a molecular weight of 145 , while the molecular weight of $\mathbf{3 a}, \mathbf{5 a}, \mathbf{6 a}$ and $7 \mathbf{a}$ is 179 , which is 34 mass units larger than the substrates, indicating that they are indeed the chlorinated products.

To obtain sufficient amounts of chlorinated products for NMR spectroscopic analysis, we used a whole-cell biotransformation approach. A total of $15 \mathrm{mg}$ of $\mathbf{3}, \mathbf{5}, \mathbf{6}$ and $\mathbf{7}$ were separately fed into $500 \mathrm{~mL}$ of IPTG-induced fermentation broth of $E$. coli BL21(DE3)/pFC56, from which $4 \mathrm{mg}$ of 3a, $3.2 \mathrm{mg}$ of 5a, 4.5 $\mathrm{mg}$ of $\mathbf{6 a}$ and $4.3 \mathrm{mg}$ of $7 \mathbf{a}$ were isolated in pure form, respectively.

The purified products were dissolved in methanol- $d_{4}$ and the NMR spectra were acquired on a Bruker AvanceIII HD Ascend500 NMR instrument. To determine the chlorination position for each product, ${ }^{1} \mathrm{H}$ (Figures S3-S6), DEPTQ-135 (Figures S7-S10), HSQC, HMBC and ${ }^{1} \mathrm{H}-{ }^{1} \mathrm{H}$ COSY spectra were recorded. The proton and carbon signals were assigned and are listed in Tables 1 and 2.

The ${ }^{1} \mathrm{H}$ NMR spectrum of $\mathbf{3 a}$ showed five proton signals, including two doublet proton signals ( $\delta 7.99$ and 8.17), an overlapped signal $(2 \mathrm{H}, \delta 7.63-7.70)$, and a singlet $(\delta 8.62)$. This is one proton less than the substrate, indicating that one of the $\mathrm{CH}$ of 3-hydroxyquinoline was chlorinated. The ${ }^{1} \mathrm{H}-{ }^{1} \mathrm{H}$ COSY spectra showed a spin system that consists of the two doublet signals and two overlapped proton signals, which suggested that the halogenation did not occurred on the benzene ring and thus one of the protons on the pyridine ring was substituted by a chlorine atom. This was supported by the presence of the singlet signal, which was assigned to $\mathrm{H}-2$ according to the HMBC correlations (Figure 4$)$ of this proton to C-4 $(\delta 102.9)$ and C-8a $(\delta$ 102.2). Thus, it can be deduced that the halogenation occurred at C-4 position, which is ortho to the hydroxyl group (Figure 4).

Table 2. ${ }^{13} \mathrm{C}(125 \mathrm{MHz}) \mathrm{NMR}$ data for 3a, 5a, 6a and $7 \mathbf{a}\left(\mathrm{CD}_{3} \mathrm{OD}, \delta\right.$ in ppm)

\begin{tabular}{cllll}
\hline Position & \multicolumn{1}{c}{ 3a } & \multicolumn{1}{c}{ 5a } & \multicolumn{1}{c}{ 6a } & \multicolumn{1}{c}{ 7a } \\
\hline 2 & $142.5(\mathrm{CH})$ & $149.9(\mathrm{CH})$ & $147.9(\mathrm{CH})$ & $150.2(\mathrm{CH})$ \\
3 & $148.2(\mathrm{C})$ & $120.6(\mathrm{CH})$ & $122.1(\mathrm{CH})$ & $119.2(\mathrm{CH})$ \\
4 & $102.9(\mathrm{C})$ & $131.7(\mathrm{CH})$ & $130.4(\mathrm{CH})$ & $137.3(\mathrm{CH})$ \\
$4 \mathrm{a}$ & $107.3(\mathrm{C})$ & $126.5(\mathrm{C})$ & $126.9(\mathrm{C})$ & $124.1(\mathrm{C})$ \\
5 & $122.5(\mathrm{CH})$ & $156.4(\mathrm{C})$ & $112.0(\mathrm{C})$ & $127.3(\mathrm{CH})$ \\
6 & $127.9(\mathrm{CH})$ & $94.8(\mathrm{C})$ & $151.2(\mathrm{C})$ & $118.8(\mathrm{CH})$ \\
7 & $126.9(\mathrm{CH})$ & $119.8(\mathrm{CH})$ & $121.3(\mathrm{CH})$ & $155.3(\mathrm{C})$ \\
8 & $128.2(\mathrm{CH})$ & $130.7(\mathrm{CH})$ & $129.6(\mathrm{CH})$ & $113.8(\mathrm{C})$ \\
$8 \mathrm{a}$ & $102.2(\mathrm{C})$ & $143.8(\mathrm{C})$ & $144.0(\mathrm{C})$ & $145.2(\mathrm{C})$ \\
\hline
\end{tabular}

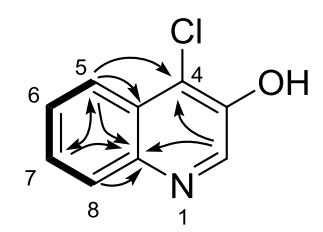

3-Hydroxy-4-chloroquinoline (3a)

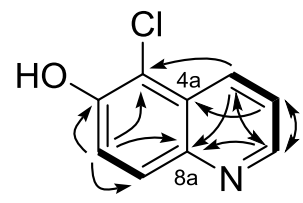

5-Chloro-6-hydroxyquinoline (6a)

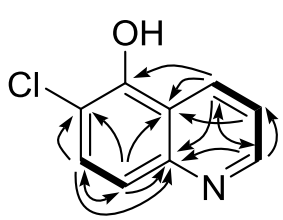

5-Hydroxy-6-chloroquinoline (5a)

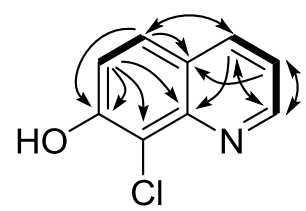

7-Hydroxy-8-chloroquinoline (7a)

\section{$-{ }^{1} \mathrm{H}^{-}{ }^{1} \mathrm{H} \mathrm{COSY} \longrightarrow \mathrm{HMBC}$}

Figure 4. Selected ${ }^{1} \mathrm{H}-{ }^{1} \mathrm{H}$ COSY and $\mathrm{HMBC}$ correlations of 3a, 5a, 6a and $7 \mathbf{a}$.

This was further supported by the HMBC correlations of H-5 ( $\delta$ 8.17) to C-4. Thus, 3a was identified as 3-hydroxy-4chloroquinoline.

The ${ }^{1} \mathrm{H}$ and DEPTQ-135 NMR of 5a also showed five $\mathrm{CH}$ signals, confirming that one proton of the substrate $\mathbf{5}$ was chlorinated. The signal of $\mathrm{H}-2$ can be easily located in the low field at $\delta$ 8.83. Two spin systems were observed in the ${ }^{1} \mathrm{H}-{ }^{1} \mathrm{H}$ COSY spectrum (Figure 4). The $\mathrm{CH}-\mathrm{CH}-\mathrm{CH}$ system belongs to the pyridine ring, which includes $\mathrm{H}-2(\delta 8.83, \mathrm{~d}), \mathrm{H}-3(\delta 7.56, \mathrm{dd})$ and $\mathrm{H}-4(\delta 8.72, \mathrm{~d})$. The $\mathrm{CH}-\mathrm{CH}$ system consists of two protons from the benzene ring, including the proton signals at $\delta 7.55$ (d) and $\delta 7.68$ (d). Thus, we concluded that that one of the protons of the benzene ring was substituted by a chlorine atom. The large coupling constant of $9.0 \mathrm{~Hz}$ indicated that the two $\mathrm{CH}$ groups are ortho to each other. Accordingly, the possibility of C-7 halogenation can be ruled out. Based on the HMBC correlations of both proton signals at $\delta 7.55$ and 7.68 to $\mathrm{C}-8 \mathrm{a}$ at $\delta 143.8$ (Figure 4), the chlorination site was determined to be at C-6. Thus, this product was identified as 5-hydroxy-6-chloroquinoline.

The ${ }^{1} \mathrm{H}$ and DEPTQ-135 NMR spectra of $\mathbf{6 a}$ are similar to those of $5 \mathbf{a}$. The signal of $\mathrm{H}-2$ was located in the low field at $\delta$ 8.80. With this signal, the spin system of $\mathrm{H}-2 / \mathrm{H}-3 / \mathrm{H}-4$ was identified by the ${ }^{1} \mathrm{H}-{ }^{1} \mathrm{H}$ COSY correlations (Figure 4). The other spin system consists of two doublet signals from the benzene ring that belongs to $\mathrm{H}-7$ and $\mathrm{H}-8$, as suggested by the large coupling constant of $9.0 \mathrm{~Hz}$. Accordingly, it can be deduced that C-5 of 6 was chlorinated. This was confirmed by the HMBC correlations of $\mathrm{H}-4(\delta 8.49, \mathrm{~d})$ and $\mathrm{H}-7(\delta 7.58, \mathrm{~d})$ to $\mathrm{C}-5$ at $\delta 112.0$. Therefore, $\mathbf{6 a}$ was characterized as 5-chloro-6-hydroxyquinoline.

The ${ }^{1} \mathrm{H}$ NMR spectrum of $\mathbf{7 a}$ showed five proton signals. The presence of a $\mathrm{CH}-\mathrm{CH}-\mathrm{CH}$ spin system in the ${ }^{1} \mathrm{H}-{ }^{1} \mathrm{H}$ COSY spectrum (Figure 4) indicated that none of the protons on the pyridine ring was chlorinated. The ${ }^{1} \mathrm{H}-{ }^{1} \mathrm{H}$ COSY correlations of $\mathrm{H}-5$ to $\mathrm{H}-6$, which are doublet signals at $\delta 7.79$ and 7.34 with a coupling constant of $8.9 \mathrm{~Hz}$, respectively, indicated that Rdc2 introduced a chlorine atom to $\mathrm{C}-8$. The structure was thus characterized as 7-hydroxy-8-chloroquinoline, which was supported by the HMBC correlations shown in Figure 4. 7a is a new compound.

Structural identification of the products $3 \mathbf{3}, \mathbf{5 a}, \mathbf{6 a}$ and $7 \mathbf{a}$ suggested that among the seven tested hydroxyquinolines, four were taken by Rdc2 as substrates to form the corresponding monochlorinated products. The chlorination reaction is highly specific as the position where the chlorine atom was introduced is 
ortho to the hydroxyl group of the four substrates. This is consistent with the results for isoquinolines in our previous studies. A number of pharmaceutically important molecules contain a hydroxylated or chlorinated quinoline moiety, such as quinine, quinidine, chloroquine and montelukast shown in Figure 1. Thus, the hydroxyl group and chlorine atom attached to quinoline represent important functional groups. In this work, we generated four quinoline derivatives that contain both functional groups at different positions.

In summary, the expression and purification Rdc2 in E. coli was improved in this work. In vitro reactions of Rdc2 with seven hydroxyquinolines revealed that this halogenase can halogenate four of these substrates. The corresponding products were then prepared through fermentation of the Rdc2-expressing E. coli strain with supplemented substrates. The four products were isolated and structurally characterized based on the UV, MS and NMR spectra. This work represents the first enzymatic preparation of chlorohydroxyquinolines. The results further expand the reservoir of the acceptable substrates of Rdc2, which makes it a useful biological halogenating agent in the preparation of structurally diverse halogenated molecules.

\section{Acknowledgments}

The Bruker AvanceIII HD Ascend-500 NMR instrument used in this work was funded by the National Science Foundation Award CHE-1429195.

\section{References and notes}

1. Efferth, T.; Fu, Y.-j.; Zu, Y.-g.; Schwarz, G.; Badireenath, K. V. S.; Wink, M. Curr. Med. Chem. 2016, 14, 2024-2032.

2. Foley, M.; Tilley, L. Pharmacol. Ther. 1998, 79, 55-87.

3. Achan, J.; Talisuna, A. O.; Erhart, A.; Yeka, A.; Tibenderana, J. K.; Baliraine, F. N.; Rosenthal, P. J.; D'Alessandro, U. Malar. J. 2011, 10, 144.

4. Shen, X. T.; Antzelevitch, C. Circulation 1986, 73, 1342-1353.

5. Leff, J. A.; Busse, W. W.; Pearlman, D.; Bronsky, E. A.; Kemp, J.; Hendeles, L.; Dockhorn, R.; Kundu, S.; Zhang, J.; Seidenberg, B. C.; Reiss, T. F. N. Engl. J. Med. 1998, 339, 147-152.

6. Prachayasittikul, V.; Prachayasittikul, S.; Ruchirawat, S.; Virapong, P. Drug Des. Devel. Ther. 2013, 7, 1157-1178.

7. Prati, F.; Bergamini, C.; Fato, R.; Soukup, O.; Korabecny, J.; Andrisano, V.; Bartolini, M.; Bolognesi, M. L. ChemMedChem 2016, 11, 1-13.

8. Heseltine, W. W.; Campbell, P. J. J. Trop. Med. Hyg. 1960, 63, 163-165.

9. Cosgrove, R. F.; Baines, S. Antimicrob. Agents Chemother. 1978, $13,540-541$.

10. Samant, B. S.; Saraf, Y. P.; Bhagwat, S. S. J. Colloid Interface Sci. 2006, 302, 207-213.

11. van Pee, K. H.; Patallo, E. P. Appl. Microbiol. Biotechnol. 2006, $70,631-641$.

12. Heemstra, J. R., Jr.; Walsh, C. T. J. Am. Chem. Soc. 2008, 130, 14024-14025.

13. Menon, B. R. K.; Latham, J.; Dunstan, M. S.; Brandenburger, E.; Klemstein, U.; Leys, D.; Karthikeyan, C.; Greaney, M. F.; Shepherd, S. A.; Micklefield, J. Org. Biomol. Chem. 2016, 14, 9354-9361

14. Zeng, J.; Zhan, J. ChemBioChem 2010, 11, 2119-2123.

15. Zeng, J.; Lytle, A. K.; Gage, D.; Johnson, S. J.; Zhan, J. Bioorg. Med. Chem. Lett. 2013, 23, 1001-1003. 


\section{Graphical Abstract}

To create your abstract, type over the instructions in the template box below.

Fonts or abstr

\section{Selective Biochlorination of hydroxyquinolines} by a flavin-dependent halogenase

Fuchao Xu ${ }^{\text {a }}$, Amanda Merkley ${ }^{a}$, Dayu Yu ${ }^{\text {b }}$, Jixun Zhan ${ }^{\text {a, }}$

Leave this area blank for abstract info.
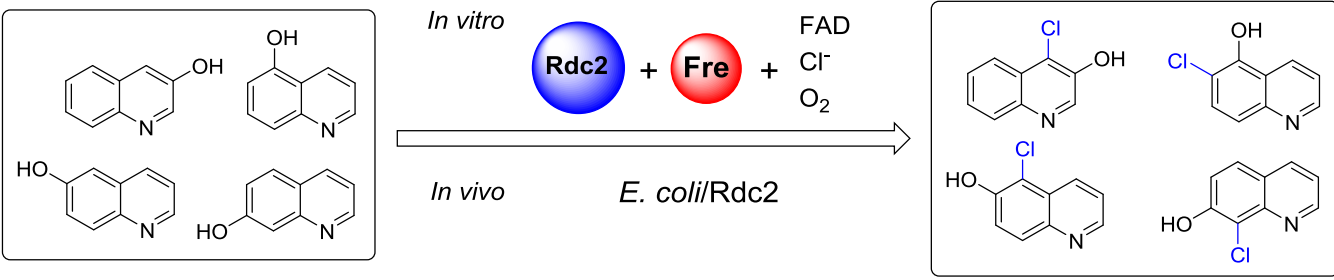